Obere Extremität 2019 · 14:48-52 https://doi.org/10.1007/s11678-018-0488-7 Received: 28 August 2018

Accepted: 28 September 2018

Published online: 23 October 2018

(c) The Author(s) 2018

CrossMark

Fractures of the olecranon represent a common elbow pathology and comprise around $1 \%$ of all fractures in the adult patient. The incidence of olecranon fractures is reported to be approximately $11.5 / 100,000 / y e a r$.

Most olecranon fractures are displaced fractures while up to $12 \%$ are stable undisplaced fractures $[2,11,13,14,17]$. Open reduction and internal fixation (ORIF) is considered the gold standard of treatment for olecranon fractures $[6,15]$. Tensionband wiring (TBW) is most commonly used for simple olecranon fractures while complex fractures are mainly addressed with plate fixation $[1,4,6,12,19]$.

\section{》) Complication rates after operative treatment are increased in the elderly}

Complication rates after operative treatment are considerably increased in the elderly patient $[3,4]$. As a result, nonoperative treatment of olecranon fractures in the elderly has been advocated in recent years by several authors $[3,5$, $8,18]$. In low-demand elderly patients in particular, nonoperative therapy may lead to satisfactory results, while active patients may still benefit from surgery. However, conclusive information regarding the clinical outcome of nonoperative management in these patients is lacking thus far. Hence, the aim of the present study was to analyze the clinical results of nonoperative treatment of olecranon fractures in the elderly patient by means of a systematic review of the literature.

Maximilian Lenz $(\mathbb{D}$ - Kilian Wegmann · Lars Peter Müller · Michael Hackl

Department of Orthopaedic and Trauma Surgery, University Hospital of Cologne, Cologne, Germany

\title{
Nonoperative treatment of olecranon fractures in the elderly-a systematic review
}

\section{Methods \\ Inclusion criteria}

We systematically reviewed the available literature covering the treatment of olecranon fractures in the elderly patient. The systematic review presented here is structured according to the PRISMA guidelines [9, 10]. The PubMed database was searched for randomize controlled studies and observational studies including retrospective and prospective studies. The following keywords were used for the search on 12 May 2018: "olecranon fracture" and in combination "olecranon fracture non-operative," "olecranon fracture non-surgical," "olecranon fracture elderly patients," and "olecranon fracture geriatric patients.. Titles and abstracts of potentially relevant articles identified by the electronic search were reviewed. We included studies regarding the clinical outcome of conservative treatment in elderly patients of a minimum age of 70 years.

\section{Exclusion criteria}

Exclusion criteria were studies presenting patients younger than 70 years. Case reports, review articles, and experimental investigations were not included in the evaluation.

\section{Study selection}

To include and exclude studies according to the aforementioned criteria, one reviewer (M.L.) searched the titles and abstracts of all identified publications and, where necessary, the full text of each ar- ticle along with its references. Discrepancies were resolved by discussion with a second reviewer (M.H.).

\section{Data extraction}

Data from the included studies were analyzed by two reviewers (M.L. and M.H.). For primary outcome parameters, the Disability of the Arm, Shoulder and Hand (DASH) score and the Mayo Elbow Performance Index (MEPI) were used. Secondary outcome parameters were complications, pain (according to the visual analogue scale [VAS]), range of motion (ROM), and any other scoring system (Broberg and Morrey, Oxford). The risk of bias in the included studies was analyzed using the Cochrane Risk of Bias Tool [7].

\section{Statistical analysis}

Statistical analysis was performed using Microsoft Excel for all published cases of nonoperatively treated olecranon fractures for primary and secondary outcome parameters as mentioned earlier, and mean scores were extracted when case data were published.

\section{Results}

An outline of the literature research is provided in - Fig. 1. Overall, one randomized controlled trial (RCT), one prospective, and two retrospective case series with a total sample size of $70 \mathrm{pa}$ tients were included.

In 1999, Veras del Monte et al. presented a retrospective case series analyzing the results of nonoperative treat- 


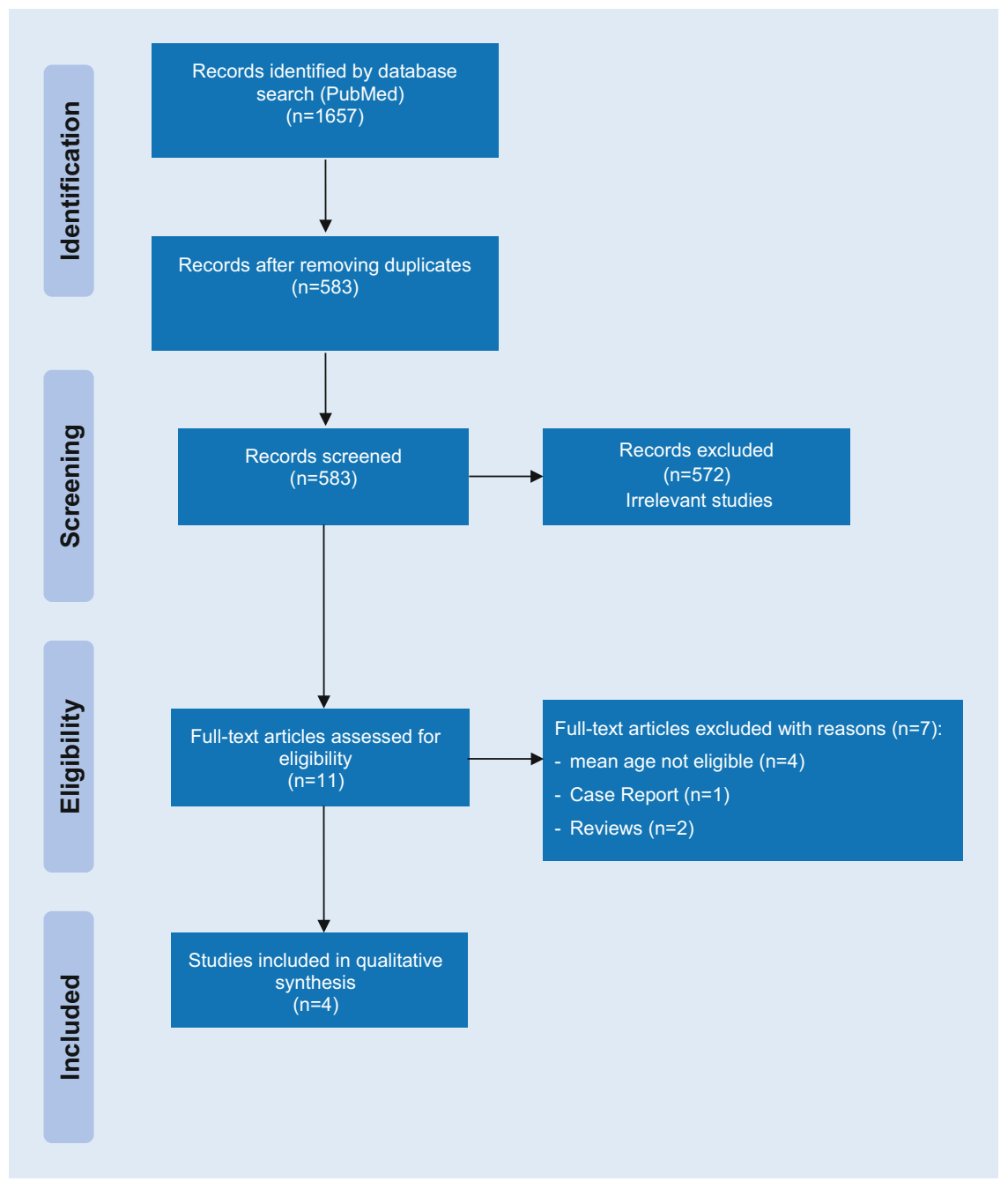

Fig. $1 \Delta$ PRISMA flow chart for literature research and analysis

ment of displaced olecranon fractures in elderly patients with a minimum age of 70 years. Their conservative treatment comprised immobilization of the upper arm with the elbow at $90^{\circ}$ for a mean period of 4.1 weeks (range: 1-12) and physiotherapy. They analyzed $12 \mathrm{pa}-$ tients with a mean age of 81.8 years (range: 73-90) and a mean follow-up of 15 months (range: 6-33). According to the Parker score, the following outcomes were observed: eight good, three fair, and one poor outcome. One patient developed degenerative arthropathy and one had sore skin that healed without any consequences. No other outcome parameters were reported in their study ([18]; - Table 1).

Gallucci et al. presented a retrospective case series in 2014 with a cohort of 28 patients after nonoperative treatment during movement of the elbow in two of 28 patients (7.1\%), and five other patients mentioned a click when moving the elbow (18.8\%). Fibrous nonunion was detected in $85 \%$ of all cases, which is slightly more than the findings of Veras del Monte et al., who reported a nonunion rate of around 70\% [5].

In 2017, Duckworth et al. presented the first and only RCT regarding the conservative treatment of olecranon fractures in elderly patients with a minimum age of 75 years. The patients were randomized to nonoperative $(n=8)$ or operative ( $n=11$; TBW $n=9$, nonlocking plate $n=2)$ treatment; the mean age of all patients was 83 years (range: 75-92). Follow-up was conducted at 6 weeks as well as at 3,6 , and 13 months.

The mean DASH score was 23 (range: $0-59)$ in the nonoperative and 22 (range: 2.5-57.8) in the operative group $(p=0.763)$. The mean MEPI score was 95 in both cohorts $(p=0.906)$. The mean Broberg and Morrey score was 88 (range: 66-100) for the conservative group and 94 (range: $80-100$ ) for the operative group $(p=0.285)$. Operatively treated patients had a significantly better mean arc of flexion $\left(129^{\circ}\right.$ vs. $\left.106^{\circ} ; p=0.049\right)$. However, the operative cohort had significantly higher complication rates $(81.8 \%$ vs. $14.3 \%$; $p=0.013)$, with most patients having loss of reduction (54.5\%) or symptomatic hardware that needed removal (27.3\%). Only one patient in the conservative group developed a complication and had to be operatively revised owing to a concomitant radial head fracture and subsequent infection. The trial was stopped prematurely after the recruitment of 19 patients because of the high complication rate in the operative treatment cohort [3].

The most recent case series by Marot et al. was published in 2018. They prospectively analyzed 22 patients with a minimum age of 75 years and a followup of 6 months. The mean MEPI score was 95.3 and the mean DASH score was 4.3 (range: 0-29.55). The mean flexion was $135^{\circ}$ (range: $130-140^{\circ}$ ) while the mean extension lag was $15^{\circ}$ (range: $5-30^{\circ}$ ). Mean pain levels according to the VAS were 1 (range: $0-3$ ). Corroborating the other studies, 18 of $22(82 \%)$ 
Obere Extremität 2019 · 14:48-52 https://doi.org/10.1007/s11678-018-0488-7

(c) The Author(s) 2018

\section{Lenz · K. Wegmann · L. P. Müller · M. Hackl}

\section{Nonoperative treatment of olecranon fractures in the elderly-a systematic review}

\section{Abstract}

Background. Most olecranon fractures are treated with open reduction and internal fixation (ORIF) leading largely to good clinical results. However, some studies have reported increased complication rates in the elderly. Therefore, nonoperative treatment of olecranon fractures in the elderly patient has been investigated by several authors in recent years. The aim of this study was to evaluate the clinical results of nonoperative treatment of olecranon fractures in elderly patients by means of a systematic review of literature. Methods. We systematically reviewed the literature on nonoperative treatment of olecranon fractures in patients with a minimum age of 70 years. Primary outcome parameters investigated were the Mayo Elbow Performance Index (MEPI) and the Disabilities of the Arm, Shoulder and Hand (DASH) score. Secondary outcome parameters were pain, range of motion (ROM), development of nonunion, and complications.

Results. Two retrospective case series, one prospective case study, and one randomized controlled trial were included $(n=70)$. The mean follow-up was 10.7 months. All studies reported good clinical results for nonoperative treatment of olecranon fractures. The mean MEPI was 95.1 and the mean DASH score was 12.3. Mean flexion of the elbow was $133^{\circ}\left(106-140^{\circ}\right)$ with a mean lag of extension of $15^{\circ}$. The operative cohort showed a significantly increased complication rate. Conclusion. Nonoperative treatment of olecranon fractures seems to provide acceptable clinical results in the elderly. However, the literature on the treatment of olecranon fractures in elderly patients is limited. While ORIF remains the gold standard, nonoperative treatment should be considered in the elderly patient in light of the recently published literature.

Keywords

Elbow joint - Osteosynthesis, fracture $\cdot$ Open fracture reduction. Nonoperative treatment . Elderly

\section{Nichtoperative Behandlung von Olekranonfrakturen des älteren Patienten - systematische Übersicht}

\section{Zusammenfassung}

Hintergrund. Die meisten Olekranonfrakturen werden mittels offener Reposition und Fixateur interne (ORIF) behandelt, was im Wesentlichen zu guten Ergebnissen führt. Allerdings wurde in einigen Studien über erhöhte Komplikationsraten bei älteren Patienten berichtet. Daher wurde in den letzten Jahren die konservative Behandlung von Olekranonfrakturen bei älteren Patienten von verschiedenen Autoren untersucht. Ziel der vorliegenden Studie war es, die klinischen Ergebnisse der konservativen Behandlung von Olekranonfrakturen bei älteren Patienten anhand einer systematischen Übersicht über die Literatur zu ermitteln.

Methoden. Dazu durchsuchten die Autoren die Literatur zur konservativen Behandlung von Olekranonfrakturen bei älteren Patienten mit einem Mindestalter von 70 Jahren.
Primäre Endpunkte waren der Mayo Elbow Performance Index (MEPI) und der Wert im Fragebogen Disabilities of the Arm, Shoulder and Hand (DASH). Sekundäre Endpunkte waren Schmerz, Bewegungsumfang (,range of motion", ROM), Entwicklung einer Pseudarthrose und Komplikationen. Ergebnisse. In die Auswertung wurden 2 retrospektive Fallserien, eine prospektive Fallstudie und eine randomisierte kontrollierte Studie eingeschlossen $(n=70)$. Die mittlere Nachbeobachtungsdauer betrug 10,7 Monate. In allen Studien wurde über gute klinische Ergebnisse für die nichtoperative Therapie von Ellbogenfrakturen berichtet. Durchschnittlich betrug der MEPI 95,1 und der DASH-Score 12,3. Die mittlere Flexion des Ellbogens lag bei $133^{\circ}\left(106-140^{\circ}\right)$ mit einem durchschnittlichen Rückstand bei der Extension von $15^{\circ}$. In der operativen Kohorte zeigte sich eine signifikant erhöhte Komplikationsrate.

Schlussfolgerung. Die konservative

Behandlung von Olekranonfrakturen scheint zu annehmbaren klinischen Ergebnissen bei älteren Patienten zu führen. Jedoch ist die Literatur zur Behandlung von Olekranonfrakturen bei älteren Patienten begrenzt. Die Behandlung mittels ORIF bleibt zwar der Goldstandard, aber angesichts der kürzlich publizierten Literatur sollte die konservative Behandlung bei älteren Patienten erwogen werden.

\section{Schlüsselwörter}

Ellbogengelenk - Osteosynthese, Fraktur . Offene Frakturreposition - Konservative Therapie · Ältere Personen fractures showed nonunion. No local or general complications are mentioned for the 22 patients in the study [8].

\section{》) Operative treatment may be still preferred for the active elderly patient}

Summarizing all reported cases of nonoperatively treated olecranon fractures, a mean MEPI score of 95.1 and a mean
DASH score of 12.3 is described for 58 patients with a mean age of 83.9 years. Regarding ROM, a mean flexion of $133^{\circ}$ (range: $106-140^{\circ}$ ) was achieved. The mean extension lag was $15^{\circ}$ (range: $\left.0-30^{\circ}\right)$. Mean pain levels according the VAS were 1 (range: $0-8$ ). In total, $80.8 \%$ of patients developed fibrous nonunion of their olecranon fractures. Other complications of nonoperative treatment were local pain $(n=8)$ and pain during movement $(n=2)$ and clicking when moving the elbow $(n=5)$. One patient presented with radial head subluxation that needed subsequent operative treatment and revision because of infection of the elbow. Owing to short follow-up periods, conclusive information regarding the rate of posttraumatic osteoarthritis is lacking.

\section{Discussion}

Open reduction and internal fixation represents the gold standard of treatment for 


\begin{tabular}{|c|c|c|c|c|c|c|c|c|c|}
\hline Author & Year & SD & $n$ & $\begin{array}{l}\text { Mean } \\
\text { age }\end{array}$ & FU & INT & POP & SOP & Bias \\
\hline $\begin{array}{l}\text { Veras del Monte } \\
\text { et al. [18] }\end{array}$ & 1999 & CS & 12 & $\begin{array}{l}82 \\
(73-90)\end{array}$ & $\begin{array}{l}15 \\
(6-33)\end{array}$ & Nonoperative & - & $\begin{array}{l}\text { Parker } 8 \text { good, } 3 \text { fair, } \\
1 \text { poor, } 9 \text { fibrous union/ } \\
\text { nonunion ( } 69 \%), 92 \% \\
\text { excellent satisfaction } \\
67 \% \text { pain free }\end{array}$ & $\begin{array}{l}\text { High risk: selec- } \\
\text { tion, performance, } \\
\text { attrition, recall bias } \\
\text { Unclear risk: re- } \\
\text { porting bias }\end{array}$ \\
\hline Gallucci et al. [5] & 2014 & CS & 28 & $\begin{array}{l}82 \\
(71-91)\end{array}$ & $\begin{array}{l}16 \\
(12-26)\end{array}$ & Nonoperative & $\begin{array}{l}\text { Mean MEPI } \\
95.0(85-100) \\
\text { Mean DASH } \\
15.43(0-43)\end{array}$ & $\begin{array}{l}\text { Parker } 25 \text { good, } 3 \text { fair; } \\
85 \% \text { fibrous union/ } \\
\text { nonunion, MRC } \\
\text { grading } 4 \text { extension } 35 \% \text {, } \\
\text { mean satisfaction score } \\
9 / 10 \text {, mean VAS score } 1 \\
(0-8)\end{array}$ & $\begin{array}{l}\text { High risk: selec- } \\
\text { tion, performance, } \\
\text { attrition, recall bias } \\
\text { Unclear risk: re- } \\
\text { porting bias }\end{array}$ \\
\hline Duckworth et al. [3] & 2017 & RCT & 19 & $\begin{array}{l}\text { INT: } 80 \\
(75-91) \\
\text { CG: } 85 \\
(79-92)\end{array}$ & 12 & $\begin{array}{l}\text { Nonoperative } \\
\text { vs. operative }\end{array}$ & $\begin{array}{l}\text { No significant } \\
\text { difference after } \\
\text { FU (DASH/ } \\
\text { MEPI) }\end{array}$ & $\begin{array}{l}\text { Arc of flexion } \\
\text { significantly better in CG } \\
\left(129^{\circ} \text { vs. } 106^{\circ} ; p=0.049\right)\end{array}$ & $\begin{array}{l}\text { High risk: perfor- } \\
\text { mance bias } \\
\text { Unclear risk: selec- } \\
\text { tion bias }\end{array}$ \\
\hline Marot et al. [8] & 2018 & CS & 22 & $\begin{array}{l}88.8 \\
(77-95)\end{array}$ & 6 & Nonoperative & $\begin{array}{l}\text { MEPI 95.3 } \\
(85-100) \\
\text { QuickDASH } 4.3 \\
(0-29.55)\end{array}$ & $\begin{array}{l}\text { Mean ROM: Flexion } 135 \\
(130-140) \text { Extension } 15 \\
(5-30) ; \text { mean VAS } 1 \\
(0-3), 18 \text { of } 22 \text { nonunion } \\
(82 \%)\end{array}$ & $\begin{array}{l}\text { High risk: selec- } \\
\text { tion, performance, } \\
\text { attrition, recall bias } \\
\text { Unclear risk: re- } \\
\text { porting bias }\end{array}$ \\
\hline
\end{tabular}

olecranon fractures in adults. In the lowdemand elderly patient, however, nonoperative treatment leads to a satisfactory clinical outcome in most cases when considering outcome scores, pain levels, $\mathrm{ROM}$, and complication rates. While nonunion is a common sequela of nonoperative treatment, it does not seem to impair low-demand patients in activities of daily living according to the available literature. Given the significantly lower complication rates when compared with operative treatment as described by Duckworth et al., nonoperative treatment of olecranon fractures should be strongly considered in these patients [3]. On the other hand, operative treatment seems to be more reliable in restoring $\mathrm{ROM}$ and extension strength, and may thus still be preferred over conservative therapy in the active elderly patient.

The fact that fracture morphology was not taken into account by any of the included studies has to be considered a noteworthy confounding factor. Small proximal avulsion fractures, which are commonly seen in elderly patients with reduced quality of bone, are difficult to address by either TBW or plate fixation and may explain the high rate of secondary displacement following ORIF in the RCT published by Duckworth et al. [3]. Especially in these patients, conservative treatment may be propagated in the future. When more solid fracture fragments are present, ORIF might still be indicated to reduce the risk of impaired function. Moreover, ORIF was performed without using modern locking plate systems and without additional tricep augmentation, which may lead to fewer perioperative complications. Furthermore, no difference was made regarding the pretrauma activity levels of elderly patients. Therefore, a definitive conclusion should not be made for elderly active patients when confronted with olecranon fractures and the indication for surgery should still be an individual decision. The limited number of studies found by this systematic review presents another limitation of this work. Further limitations of the present study should also be mentioned. Most observational studies were retrospective with a high risk of selection bias. With the premature ter- mination of the RCT, comparability of the cohorts is lacking. Furthermore, the operative group was predominantly treated with TBW. Therefore, no relevant conclusions can be drawn when comparing conservative treatment with plate fixation. Finally, owing to a rather short mean follow-up of only 10.7 months, the longterm outcome of nonoperative treatment could not be assessed.

Regarding the results of this systematic review, additional research with randomized controlled multicenter trials involving larger sample sizes and longer followup are necessary. In 2015, Symes et al. announced their clinical trial of surgery for olecranon fractures in elderly patients (SOFIE; [16]). The trial is focused on patients with a minimum age of 75 years and will analyze the DASH scores with a follow-up of 12 months. Hopefully, this trial will further elucidate the role of nonoperative treatment of olecranon fractures in elderly patients.

In summary, the available literature reports satisfactory clinical results of nonoperative treatment of olecranon fractures in the low-demand elderly patient. 
While certain limitations apply, nonoperative treatment has to be considered when dealing with these patients. Further research is necessary, however, to elucidate which fracture patterns benefit the most from nonoperative management.

\section{Practical conclusion}

- Olecranon fractures are a common elbow injury in elderly patients.

- Complications of operative treatment in elderly patients should be considered.

- The indication for operative or conservative treatment should be an individual decision based on a variety of factors.

- Nonoperative treatment of olecranon fractures in elderly patients can achieve good clinical outcome.

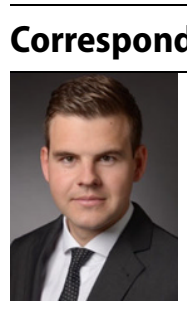

Maximilian Lenz

Department of Orthopaedic and Trauma Surgery, University Hospital of Cologne

Kerpener Str. 62, 50937 Cologne, Germany maximilian.lenz@uk-koeln.de

\section{Compliance with ethical guidelines}

Conflict of interest. L.P. Müller and K. Wegmann are consultants for Arthrex (Germany). Research support by Medartis (Switzerland) and Arthrex (M. Hackl, K. Wegmann, L.P. Müller). Research fellowship of Arthrex (M. Hackl). M. Lenz declares that he has no competing interests.

This article does not contain any studies with human participants or animals performed by any of the authors.

Open Access This article is distributed under the terms of the Creative Commons Attribution 4.0 International License (http://creativecommons.org/licenses/by/ 4.0/), which permits unrestricted use, distribution, and reproduction in any medium, provided you give appropriate credit to the original author(s) and the source, provide a link to the Creative Commons license, and indicate if changes were made.

\section{References}

1. BrinkPR, Windolf M, De Boer P et al (2013) Tension band wiring of the olecranon: is it really a dynamic principle of osteosynthesis? Injury 44:518-522
2. Duckworth AD, Clement ND, Aitken SA et al (2012) The epidemiology of fractures of the proximal ulna. Injury 43:343-346

3. Duckworth AD, Clement ND, Mceachan JE et al (2017) Prospective randomised trial of nonoperative versus operative management of olecranon fractures in the elderly. Bone Joint J 99B:964-972

4. Duckworth AD, Clement ND, White TO et al (2017) Plate versus tension-band wire fixation for olecranon fractures: a prospective randomized trial. J Bone Joint Surg Am 99:1261-1273

5. Gallucci GL, Piuzzi NS, Slullitel PA et al (2014) Non-surgical functional treatment for displaced olecranon fractures in the elderly. Bone Joint J 96B:530-534

6. Gruszka D, Arand C, NowakT etal (2015) Olecranon tension plating or olecranon tension band wiring? A comparative biomechanical study. Int Orthop 39:955-960

7. Higgins JPT, Green S, Cochrane Collaboration (2008) Cochrane handbook for systematic reviews of interventions. Wiley-Blackwell, Chichester, Hoboken

8. Marot V, Bayle-Iniguez X, Cavaignac E et al (2018) Results of non-operative treatment of olecranon fracture in over 75-year-olds. Orthop Traumatol Surg Res 104:79-82

9. Moher D, Liberati A, Tetzlaff J et al (2010) Preferred reporting items for systematic reviews and metaanalyses: the PRISMA statement. Int J Surg 8:336-341

10. Page MJ, Moher D (2017) Evaluations of the uptake and impact of the Preferred Reporting Items for Systematic reviews and Meta-Analyses (PRISMA) Statement and extensions: a scoping review. Syst Rev 6:263

11. Powell AJ, Farhan-Alanie OM, Bryceland JK et al (2017) The treatment of olecranon fractures in adults. Musculoskelet Surg 101:1-9

12. Ries C, Wegmann K, Meffert RH et al (2015) Doubleplate osteosynthesis of the proximal ulna. Oper Orthop Traumatol 27:342-356

13. Romero JM, Miran A, Jensen CH (2000) Complications and re-operation rate after tensionband wiring of olecranon fractures. J Orthop Sci 5:318-320

14. Rommens PM, Kuchle R, Schneider RU et al (2004) Olecranon fractures in adults: factors influencing outcome. Injury 35:1149-1157

15. Schliemann B, Raschke MJ, Groene P et al (2014) Comparison of tension band wiring and precontoured locking compression plate fixation in Mayo type IIA olecranon fractures. Acta Orthop Belg 80:106-111

16. Symes M, Harris IA, Limbers J et al (2015) SOFIE: Surgery for Olecranon Fractures in the Elderly: a randomised controlled trial of operative versus non-operative treatment. BMC Musculoskelet Disord 16:324

17. Veillette CJ, Steinmann SP (2008) Olecranon fractures. Orthop Clin North Am 39:229-236

18. Veras Del Monte L, Sirera Vercher M, Busquets Net Ret al (1999) Conservative treatment of displaced fractures of the olecranon in the elderly. Injury 30:105-110

19. Wolfgang G, Burke F, Bush D et al (1987) Surgical treatment of displaced olecranon fractures by tension band wiring technique. Clin Orthop Relat Res 1987(224):192-204 